\title{
THE POWER OF ABILITY-MOTIVATION-OPPORTUNITY ENHANCING HUMAN RESOURCE MANAGEMENT PRACTICES ON ORGANIZATIONAL ETHICAL CLIMATE
}

\author{
Lee-Chin Tay* \\ Universiti Utara Malaysia \\ Fee-Yean Tan \\ Universiti Utara Malaysia \\ Khulida Kirana Yahya \\ Universiti Utara Malaysia
}

\begin{abstract}
This paper examined ability-, motivation- and opportunity-enhancing human resource management (HRM) practices to achieve organizational ethical climate. Sample sizes of 74 construction companies in Malaysia were selected based on systematic sampling technique. Partial Least Square Structural Equation Modelling (PLS-SEM) of SmartPLS 3.2.6 software was used to analyse the data. The findings revealed that ability-enhancing HRM practices was related to organizational ethical climate, while motivation- and opportunity-enhancing HRM practices did not influence organizational ethical climate. This denoted that ability-enhancing HRM practices played an important role in promoting organizational ethical climate of construction companies in Malaysia. In addition, discussion, implications, directions for future research, and conclusion of the study were also highlighted.
\end{abstract}

Keywords: Human Resource Management Practices; Organizational Ethical Climate.

\section{INTRODUCTION}

With the expectations from the stakeholders (e.g government and customer), organizations were increasingly committed to improve environmental preservation (Martin-de Castro, Amores-Salvado, Navas-Lopez \& Balarezo-Nunez, 2017; Jang, Zheng \& Bosselman, 2017; Theodoulidis, Diaz, Crotto \& Rancati, 2017). Vilchez, Darnall and Aragon-Correa (2017) discussed how different stakeholders (i.e managers, public protests and mass media) influenced organizations' environmental practices. Despite the increasing attention from the organizations, the failure rate associated with organizations' environmental practices remained high (Dubey, Gunasekaran, Childe, Papadopoulos, Hazen \& Giannakis, 2017; Eccles, Ioannau \& Serafaim, 2014). This could be ascribed to the low budget of environmental practices (Bonini, 2011; Sroufe, 2017) and poor involvement of the organizational members in environmental process (Geng, Mansouri \& Aktas, 2017; Jabbour, Mauricio \& Jabbour, 2017; Kiron, Unruh, Kruschwitz, Reeves, Rubel \& Zum Felde, 2017). Under this situation, many scholars (e.g Galpin, Whittington \& Bell, 2015; Porter, Gallagher \& Lawong, 2016; Marshall, McGGrath \& Claudy, 2015) had argued organizations could enhance environmental preservation through organizational ethical climate. Indeed, organizations developed organizational ethical climate

\footnotetext{
- Corresponding author: Phd candidate. Address: School of Business Management, Sintok, 06010, University Utara Malaysia, Kedah, Malaysia. Tel: 019-5513790. Email address: t.leechin@yahoo.com
} 
by establishing ethics values (e.g respect, responsibility and integrity) that guide organizations' attitudes and behaviors (Zientara \& Zamojska, 2016). It was believed that ethics values enhanced organizations' environmental awareness and subsequently environmental behaviors (Chan, Hon, Chan \& Okumus, 2014). For example, organizations may organize recycling programs as a result of their increased awareness of environmental problems. Unfortunately, some important questions still cannot be answered in the organizational ethical climate literatures because scant attention had been devoted to understand organizational ethical climate in particular (Guerci, Radaelli, Siletti, Cirella \& Rami Shani, 2015; Manroop, Singh \& Ezzedeen, 2014). For instances, what conditions cause organizations enhanced organizational ethical climate? And how organizations achieved organizational ethical climate? Thus, to eradicate the shortfall in the organizational ethical climate researches, this paper aimed to examine the organizational factor especially on human resource management (HRM) practices to achieve organizational ethical climate.

Besides that, various researchers (Arulrajah, 2015; Parboteeah, Seriki \& Hoegl, 2014; Thite, 2013) increasingly acknowledged HRM practices cannot be ignored when predicting and explaining organizational ethical climate. HRM practices such as recruitment and selection, training and development, compensation and benefits facilitated benevolence climate (e.g organizational ethical climate) by supporting organizational policies and procedures that encouraged organizations to concern for the natural environment (Manroop, 2015). Although researchers highlighted HRM practices influenced organizational ethical climate, little known for HRM practices' potentiality in influencing organizational ethical climate. It was observed that prior studies (e.g Durrani \& Rajagopal, 2016; Ogunfowara, 2014; Weinstein, 2012) utilized specific HRM practices rather than a set of interconnected practices that make up the comprehensive HRM practices to achieve organizational ethical climate. Shaffer, Mukhshi \& Kim (2015) focused on recruitment and selection in relation ethics policies whereas Bruns, Burtis, Gronowski, McQueen, Newman \& Jonsson (2015) examined organizational training and development on organizational ethics (e.g organizational ethical climate). Simply stated, how comprehensive HRM practices promote organizational ethical climate failed to clarify. To fill this gap, this paper introduced comprehensive HRM practices in three dimensions namely ability-motivationopportunity (AMO) HRM practices to influence organizational ethical climate as suggested by Guerci et al. (2015). Similarly, Wright, Dunford and Snell (2011) claimed that HRM practices (i.e AMOenhancing) do not operate independently but work together in a synergistic manner to achieve the goal. As such, in study this link, this paper contributed to the AMO-HRM practices and organizational ethical climate literatures in several ways. First, it improved the understanding on how AMO-HRM practices could create organizational ethical climate. Second, it explicated the under researched relationship between AMO-HRM practices and organizational ethical climate. This could inspire future researches to test on the AMO-HRM practices and organizational ethical climate. Also, this paper helped the organizations to view HRM practices in an interrelated and comprehensive way that promote organizational ethical climate. Besides that, AMO-HRM practices helped the organizations to move forward to the ethical perspective.

Moreover, this paper had several sections. Next section explained the definition of organizational ethical climate, ability, motivation and opportunity enhancing human resource management practices and the relationship between organizational ethical climate and ability, motivation and opportunity enhancing human resource management practices. This was followed by the research framework, research methodology, findings, discussion and conclusion. 


\section{LITERATURE REVIEW}

\subsection{Definition of Organizational Ethical Climate}

Schneider (1983) defined organizational ethical climate as organizational shared beliefs and values in shaping and guiding the organizational members' behavior. Victor and Cullen (1988) also had defined organizational ethical climate as perceptions of typical organizational practices and procedures that have ethical content. Meanwhile, Weber and Geder (2011) defined organizational ethical climate as a component of an organizational culture that influences organizational members on how to act appropriately. In summary, organizational ethical climate is perceived as a part of organizational culture that reflected in organizational ethical practices and procedures in guiding acceptable and unacceptable behaviors within the organizations. This view was supported by Luria and Yagil (2008), Martin and Cullen (2006), and Barnett and Vaiceys (2002) when they revealed that organizational ethical climates provided behavioral cues and reflected in organizational practices, procedures and norms. For example, when the organizational members are faced with an ethical dilemma (e.g over consumption of natural resources), their behaviors are guided by the organizational ethical procedures. Following the above discussion for the definition of Victor and Cullen's organizational ethical climate, the perceptions of typical organizational practices and procedures that have ethical content laid the foundation of this study.

\subsection{Definitions of Ability, Motivation and Opportunity Enhancing Human Resource Management Practices}

Ability-enhancing HRM practice means the organizations use recruitment and selection, training and development to increase the employees' ability to perform as expected and achieve specific organizational goals (Guerci et al., 2015). Meanwhile, according to Bello-Pintado (2015), abilityenhancing HRM practice is referred as the practices that enhance the workers' abilities to achieve organizational objectives through new hires and investment in training. Furthermore, according to Jiang, Lepak, Han, Hong, Kim \& Winkler (2012), ability-enhancing HRM practices are the practices that influence the workers' competencies via recruitment and selection, training and development. In other words, ability-enhancing HRM practices are the practices that increase the employees' abilities and competencies to achieve organizational goals. Ability-enhancing HRM practices included recruitment, selection, training and development practices (Guerci et al., 2015; Gardner, Wright \& Moynihan, 2011; Jiang et al., 2012). Recruitment and selection practices were sought to ensure searching for potential employees and choosing the right employees that match with the skills and competencies for a specific job requirement. Hence, recruitment and selection were likely to enhance the highly skilled workforce by attracting and selecting employees with higher levels of organizations relevant knowledge and skills. On the other hand, training and development practices increased the knowledge and skill of the employees within the organizations through providing employees with appropriate knowledge and skills to perform the job. Effective recruitment, selection, training and development practices helped organizations to employ and retain good workers, reduced turnover rates, and enhanced employees' morale as indicated in the previous studies (e.g Jiang et al., 2012; Subramony, 2009).

Motivation-enhancing HRM practice means that the organization uses contingent rewards and performance management to increase the employees' motivation to perform (Guerci, et al., 2015). Meanwhile, according to Bello-Pintado (2015), motivation-enhancing HRM practice is referred as the practices that enhance the workers' motivation in order to put extra effort when doing the job through rewards and performance management. Furthermore, according to Jiang et al. (2012), motivationenhancing HRM is the practices that influence employee motivation and effort to increase 
organizational performance via the compensation system and performance management. In summary, motivation-enhancing HRM practice is the practices that enhance employee motivation within the organizations to perform better. Motivation-enhancing HRM practices included contingent rewards (e.g performance based pay, piece rate systems and profit sharing systems) and performance management. Employees within the organizations are motivated to exert higher efforts in their job when their performance will be rewarded with fair pay. For example, an organization enhances the commitment of the employees within the organization in engaging ethical behaviors by rewarding them with various financial rewards. Performance management also motivates the employees within organizations to perform when the organizations provide performance standards to employees and communicate performance feedback to them. For example, an organization establishes the ethics performance standards in order to make the organizational members understand what they are supposed to do and this would dramatically improve the organizations' ethical outcomes.

Opportunity-enhancing HRM practice means that the organizations use employee involvement practices to increase the employees' opportunity to engage (Guerci, et al., 2015). Meanwhile, according to Bello-Pintado (2015), opportunities-enhancing HRM practices are referred to as the practices that delegate decision making authority and responsibility from top level hierarchy to lower level hierarchy through information sharing. On the other hand, according to Jiang et al. (2012), opportunity-enhancing HRM practices are the practices that give the opportunities to employees within organizations to exert their ability and motivation through job design. In summary, opportunity-enhancing HRM practices are the practices that increase the employees' chances to contribute in achieving organizational goals. For example, employee involvement in the decision making about ethical issues will allow the employees within the organizations to suggest how to improve the organization's ethics program. As a result, it increases organizational morale because the organizations trust their employees and appreciate the idea of the contribution of the workers. Not only that, it also benefits the organizations' growth since the existing employees within the organizations offer better ethical ideas that suit the organizations' needs to solve the organizations' ethic problems.

\subsection{Ability, Motivation and Opportunity Enhancing Human Resource Management Practices and Organizational Ethical Climate}

Previous studies (e.g Parboteeah et al., 2014; Thite, 2013; Mossholder, Richardson \& Settoon, 2011; Garavan \& McGuire, 2010; Foote \& Ruona, 2008) had recognized the importance of ability-enhancing HRM practices (i.e recruitment and selection; training and development) in improving organizational ethical climate. According to Guerci et al. (2015), organization fostered organizational ethical climate when they recruited and selected new entrance with high ethical sensitivity (i.e higher level of ethics perceptions and interpretation). Organizations hired and chose the job applicants that embraced ethical values because such job applicants were capable to exercise ethical behaviors (Guerci et al., 2015). Similarly, Arulrajah (2015) also disclosed that recruitment and selection contributed in creating and sustaining organizational ethical climate. It is likely that the potential employees that met the ethical standards of the organizations will be recruited and selected based on behavioral interviewing i.e screening applicants for ethical behavior (Arulrajah, 2015). In addition, environmental training and development change organizations' disposable of waste by recycling the waste when the organizations understand the importance of pollution prevention (Bhardwaj, 2016). This enables to achieve organizational ethical climate. Similarly, environmental education focuses on raising the organizations' awareness to protect natural resources and guide the organizations how to prevent environmental pollution (Nasibulina, 2015). Under this circumstance, organizational ethical climate is developed. On the other hand, organizational development practices increased the capabilities of organizations to 
achieve ethical objectives and enhance the ethical knowledge of organizations (Garavan \& McGuire, 2010). That was, ethics programs provided ethical behavior expectations for the organizational members to ensure them to perform the job in an ethical manner (Garavan \& McGuire, 2010).

Motivation-enhancing HRM practices (i.e rewards systems; performance appraisal) has been associated to organizational ethical climate (Arulrajah, 2015; Parboteeah et al., 2014; Thite, 2013). According to Guerci et al. (2015), rewards and compensation, one of the motivation-enhancing HRM practices, fosters organizational ethical climate by introducing punishment, sanctions, benefits (e.g pay increase, awards). This is because the employees are more likely to support ethical conduct if the employees are rewarded with monetary and non-monetary rewards (Guerci et al., 2015). Guerci, Radaelli, De Battisti and Siletti (2017) emphasized that pay and reward play a critical role in enhancing organizational ethical climate through rewarding the ethical behavior among the organizational members. Besides that, performance appraisal, one of the motivation-enhancing HRM practices, is utilized to increase organizational ethical climate (Arulrajah, 2015). Consistently, Parboteeah et al. (2014) highlighted that performance appraisal sustains organizational ethical climates through incorporating ethical behavior as the major criteria in the evaluation process. This practice directly generates strong organizational ethical climates. In addition, opportunity-enhancing HRM practices are crucial to the advancement of organizational ethical climate because they provide the organization with chances for the organizations members to engage in ethical behavior (Guerci et al., 2015). Therefore, it indicates opportunityenhancing HRM practices such as maximized employee participation and involvement practices in ethical issues can increase organizational ethical climate. Based on Guerci et al. (2015), the organizations that develop employee participation and involvement practices in ethical issues give a strong signal directly to the organizational members to attempt in more ethical behaviors. It can be implemented through motivating the employees within organizations to report any unethical behaviors (e.g release toxins, dumping pollutants) while assuring the employees within organizations that their identities would not be revealed all the times (Guerci et al., 2015). This will encourage the employees within the organization to voice out against unethical practices without fear of retaliation and will result in organizational ethical climate.

The studies revealed that ability, motivation and opportunity enhancing human resource management practices had significant relationships with organizational ethical climate, hence it is hypothesized that:

$H_{l}$ : Ability enhancing human resource management practices has significant relationship with organizational ethical climate

$\mathrm{H}_{2}$ : Motivation enhancing human resource management practices has significant relationship with organizational ethical climate

$H_{3}$ : Opportunity enhancing human resource management practices has significant relationship with organizational ethical climate

Figure 1: Research Framework

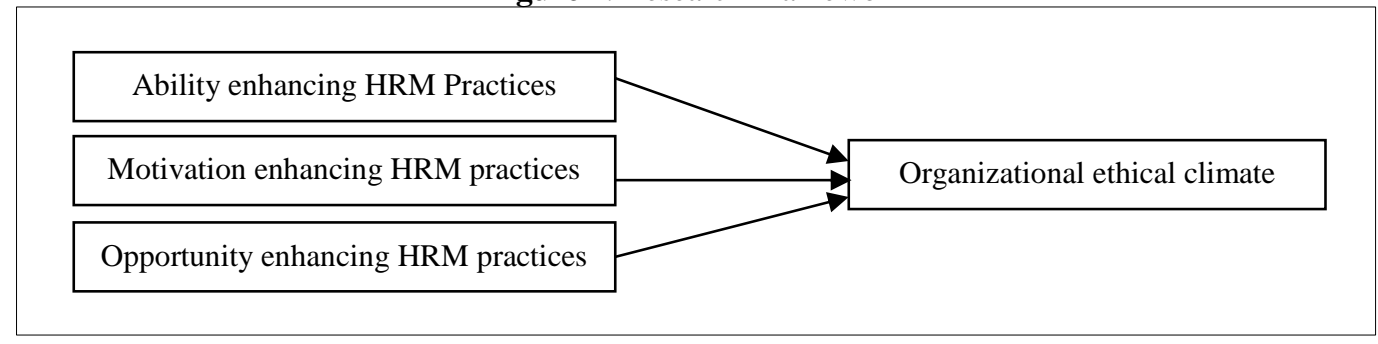


Figure 1 shows the research framework for this study. This study proposed that ability, motivation and ability enhancing human resource management practices had a direct relationship with organizational ethical climate. This was based on the Resource Based View (RBV) theory. Resource Based View (RBV) theory was introduced by Barney (1991), who pointed out that when the resources are valuable, rare, inimitable and non-substitutable, the resources can constitute to a source of sustainable competitive advantage. Under the Resource Based View (RBV) theory, organizational ethical climate is one of the important resources that needs to be possessed by organizations to compete in the market. Organizational ethical climate meets the resources criteria mentioned by Barney (1991).

Organizational ethical climate is valuable because a strong organizational ethical climate can achieve a sustained competitive advantage worth millions of dollar (Manroop et al., 2014; Barney, 1991). Furthermore, organizational ethical climate is rare and difficult to substitute since it is built and deeply embedded in the culture of the organizations (Manroop, 2015; Özçelik, Aybas \& Uyargil, 2016; Barney, 1986). As a result, it cannot be traded in the marketplace (Manroop, 2015, Barney, 1986). Not only that, organizational ethical climate is difficult to imitate by the competitors because it is accumulated over the time and difficult to duplicate in a short time (Manroop et al., 2014; Branco \& Rodrigues, 2006). Therefore, in the context of this study, organizational ethical climate was more likely to be one of the important resources of the organizations to achieve competitive advantages.

In addition, Resource Based View (RBV) theory also suggested that HRM practices play an important role in influencing organizational resources (i. e organizational ethical climate) to achieve competitive advantage (Barney, 1992; Wright \& McMahan, 1992; Reed \& DeFillippi, 1990). Previous studies (e.g Manroop, 2015; Lado \& Wilson, 1994; Wright \& McMahan, 1992; Ulrich \& Lake, 1990) also highlighted that HRM practices enhance the values of organizational resources to increase competitive advantage. In the context of this study, ability-, motivation- and opportunity-enhancing HRM practices were predicted to influence organizational ethical climate. For example, an organization implements ethics training to educate the employees within organizations about the desired ethical behaviors and directly fosters organizational ethical climate.

\section{RESEARCH METHODOLOGY}

\subsection{Research Design}

This study adopted the quantitative research methodology. Quantitative research methodology permitted large number of data collections which the results could be generalised to the whole population. Questionnaire was used as a research instrument to gather data because it allowed the researcher to collect data from a large number of targeted respondents. According to Sekaran and Bougie (2013), questionnaire had been widely used in social science research for collecting data from a large number of respondents. The questionnaires were distributed to the selected construction companies via email. Mail questionnaires cover construction companies at different states at lower costs (Abu Bakar \& Ahmad, 2010). Furthermore, the unit of analysis of this study was organizational level, because this study examined the organizational ethical climate (dependent variable) of construction companies in Malaysia. The representative (i.e executive director or managing director or human resource manager) of each participated construction companies in Malaysia served as the respondents to answer the questionnaires. 


\section{2. $\quad$ Samples}

The population of this study comprised of 1045 construction companies in Malaysia. The population list of construction companies was obtained from a directory published by the Construction Industry Development Board (CIDB) in 2016, which was the latest list of construction companies Malaysia. Besides that, according to Hamimah, Norfashiha, Norazian and Norizan (2012), construction companies were one of the most susceptible to unethical practices because it involved substantial capital investment, bribery, corruption and conflicts of interest. Hamzah, Wang and Yap (2010) identified that unethical practices were easier to occur at every stage of the construction projects, either during planning, organizing and executing construction projects. Hence, construction companies were suitable to become the target respondent in this study. Moreover, this study identified the sample size based on G*Power 3.1.9.2 with significant level of 0.05 and the power of 0.95. As claimed by Faul, Erdfelder Lang and Buchner (2007), it is the suitable software to calculate sample size in social and behavioral researchers. Hence, the desired sample size of this study was 74 .

Roscoe (1975) mentioned that sample size larger than 30 and less than 500 are suitable for most of researches. Furthermore, in order to choose the study sample, systematic sampling technique was utilized. It is done by using the sampling frame with 1045 names and addresses of construction companies in Malaysia. That is, the construction companies numbered 14, 28, 42 and 56 were selected until 74 construction companies were obtained (i.e 1045/74). However, from the total sample of 74, 50 responses $(68 \%)$ were collected. $68 \%$ response rate was considered satisfactory since Nulty (2008) revealed that $20 \%$ response rate was adequate for mail survey. The response rate was relatively better than previous studies. Raile (2012) obtained 30\% response rate meanwhile Guerci, Radaelli, Siletti, Cirella \& Rami Shani, (2015) had only 16\% response rate. The construction companies surveyed comprised of $96 \%$ Malaysian, 2\% foreign, and 2\% Malaysian-foreign ownership construction companies. Their construction businesses were run by professional management groups (52\%) and business owners (48\%). Not only that, a large percentage of construction companies had been in the industry for more than 10 years (58\%) while the rest were less than 10 years $(42 \%)$. Most of them had domestic market (72\%) followed by domestic and international markets (22\%) and also international market (6\%). They mostly had 1 to 50 employees (82\%). Only a handful had more than 50 employees $(18 \%)$.

\subsection{Measurements}

Measurements for organizational ethical climate was originally developed by Cullen, Victor and Bronson (1993) because it is considered as one of the most dominant perspectives on ethical climate (Guerci et al., 2015) and extensively adapted by most ethics researchers (e.g Parboteeah, Chen, Lin, Chen, Lee \& Chung, 2010; Parboteeah \& Kapp, 2008). The 12 items under the organizational ethical climate measured were egoist-local, benevolent-local, and principal-local ethical climates of the organizations. The 12 organizational ethical climate items were rated using a five point likert scale, ranging from 1 (mostly false) to 5 (completely true).

Moreover, HRM practices were measured by Guerci et al. (2015). The 18 items of HRM practices accessed the degree of ability-motivation-opportunity enhancing HRM practices. In this study, each of the adapted questions asked how strongly the respondent agreed or disagreed with the human resource management practices and corporate environmental citizenship statements on a five point scale, ranging from 1 (strongly disagree) to 5 (strongly agree). 


\section{RESULTS}

Partial Least Square Structural Equation Modelling (PLS-SEM) of SmartPLS 3.2.6 software was utilized for analyzing the data because it could analyse higher order research model (Becker, Klein, \& Wetzels, 2012). Higher order research model of this study had two levels: first-order and second-order constructs. First-order constructs were ability, motivation, opportunity enhancing HRM practices, egoism, benevolence and principled. On the other hand, organizational ethical climate was second-order construct (Ghosh, 2015; Lau, Tong, Lien, Hsu, 2017). Besides that, first-order constructs were reflective constructs since they are represented by their items (Mackenzie, Podsakoff and Jarvis, 2005). Take an example, items such as "Decisions in this organisation are primarily viewed in terms of contribution to profit" and "Employees are expected to do anything to further the organisations' interests" were manifestations of the egoism first-order construct. In contrast, second-order construct (i.e organizational ethical climate) was formative construct when it formed by first-order constructs (i.e egoism, benevolence and principled). Egoism, benevolence and principled formed the meaning of organizational ethical climate since they were different with each other. Thus, changing any first-order constructs changed the meaning of second-order construct. Two stages of analytical approaches, namely measurement model and structural model of PLS-SEM then was examined (Hair, Hult, Ringle \& Sarstedt, 2017). Measurement model examined the reliability and validity of the items whereas structural model accessed the relationship between the constructs (Hair et al., 2017).

\subsection{Assessment of First-order Reflective Measurement Model}

Under the first-order reflective measurement model, four tests namely item loadings, composite reliability (CR), average variance extracted (AVE) and Heterotrait-Monotrait ratio (HTMT) were carried out to examine the validity and reliability of the items. Item loadings referred to the extent to which the items correlated with the constructs (Hair et al., 2017). Composite reliability (CR) measured the construct's internal consistency reliability. Average variance extracted (AVE) revealed the degree the construct explained the items' variance (Hair et al., 2017). Heterotrait-Monotrait ratio (HTMT) detected correlations between the two constructs (Hair et al., 2017). The results were shown in Tables 1 and 2. Referring to Table 1, the majority of the item loadings for first-order reflective constructs were above the cut off value, which was 0.7 as suggested by Hulland (1999). However, EG3 and EG4 was dropped from the analysis because they had the loadings lower than 0.40 . According to Mackenzie et al. (2005), the procedure of dropping items in the reflective constructs does not alter the meaning of the constructs because they are highly correlated with each other. Moreover, composite reliability (CR) for first-order reflective constructs exceeded the minimum criteria 0.7 (Bagozzi \& Yi, 1988). Furthermore, average variance extracted (AVE) of first-order reflective constructs were greater than the required minimum value 0.5 (Bagozzi \& Yi, 1988). Finally, Heterotrait-Monotrait ratio (HTMT) of first-order reflective constructs was confirmed using HTMT 0.90 criterion, where Heterotrait-Monotrait ratio (HTMT) values of each first-order reflective construct was below HTMT ${ }_{0.90}$ criterion as depicted in Table 2. HTMT ${ }_{0.90}$ criterion was applied since it strongly pointed out the correlations between the two constructs compared HTMT 0.85 criterion (Henseler, Ringler \& Sarstedt, 2015). In brief, first-order reflective measurement model was considered as satisfactory and sufficient in reliability and validity. The next section covered the assessment of second-order formative items.

\subsection{Assessment of Second-order Formative Measurement Model}

Under the second-order formative measurement model, variance inflation factor (VIF) and the significance of formative items' outer weights are carried out (Hair et al., 2017). Variance inflation 
Table 1: Measurement model results of First-Order Reflective Constructs (i.e ability, benevolence, egoism, motivation, opportunity and principled)

\begin{tabular}{|c|c|c|c|c|}
\hline First-Order Reflective Constructs & Items & Loadings & $\mathbf{C R}$ & AVE \\
\hline \multirow[t]{6}{*}{ Ability } & ABT1 & 0.710 & 0.929 & 0.687 \\
\hline & $\mathrm{ABT} 2$ & 0.850 & & \\
\hline & ABT3 & 0.879 & & \\
\hline & ABT4 & 0.907 & & \\
\hline & ABT5 & 0.843 & & \\
\hline & ABT6 & 0.773 & & \\
\hline \multirow[t]{4}{*}{ Benevolence } & BN1 & 0.811 & 0.880 & 0.646 \\
\hline & $\mathrm{BN} 2$ & 0.811 & & \\
\hline & $\mathrm{BN} 3$ & 0.818 & & \\
\hline & $\mathrm{BN} 4$ & 0.716 & & \\
\hline \multirow[t]{4}{*}{ Egoism } & EG1 & 0.855 & 0.861 & 0.756 \\
\hline & EG2 & 0.884 & & \\
\hline & EG3 & $\dagger$ & & \\
\hline & EG4 & $\dagger$ & & \\
\hline \multirow[t]{4}{*}{ Motivation } & MTN1 & 0.864 & 0.935 & 0.781 \\
\hline & MTN2 & 0.925 & & \\
\hline & MTN3 & 0.873 & & \\
\hline & MTN4 & 0.872 & & \\
\hline \multirow[t]{7}{*}{ Opportunity } & OPTN1 & 0.817 & 0.921 & 0.625 \\
\hline & OPTN2 & 0.767 & & \\
\hline & OPTN3 & 0.763 & & \\
\hline & OPTN4 & 0.780 & & \\
\hline & OPTN5 & 0.906 & & \\
\hline & OPTN6 & 0.727 & & \\
\hline & OPTN7 & 0.760 & & \\
\hline \multirow[t]{4}{*}{ Principled } & $\mathrm{PC} 1$ & 0.912 & 0.921 & 0.744 \\
\hline & $\mathrm{PC} 2$ & 0.890 & & \\
\hline & PC3 & 0.852 & & \\
\hline & PC4 & 0.791 & & \\
\hline
\end{tabular}

Note: OEC=organizational ethical climate; $\mathrm{CR}=$ composite reliability; $\mathrm{AVE}=$ average variance extracted; $\uparrow=$ items dropped

Table 2: Heterotrait-Monotrait ratio (HTMT) Results of First-Order Constructs (i.e benevolence, egoism, motivation, opportunity and principled)

\begin{tabular}{cccccc}
\hline \hline & Ability & Benevolence & Egoism & Motivation & Opportunity \\
\hline Benevolence & 0.636 & & & & \\
Egoism & 0.236 & 0.303 & & & \\
Motivation & 0.860 & 0.587 & 0.295 & & \\
Opportunity & 0.802 & 0.461 & 0.382 & 0.900 & \\
Principled & 0.357 & 0.536 & 0.716 & 0.277 & 0.123 \\
\hline \hline
\end{tabular}

factor (VIF) examined the collinearity problems whereas the significance of formative items' outer weights checked whether formative items were contributed to form the constructs (Hair et al., 2017). Based on Table 3, variance inflation factor (VIF) values were less than 5. That was, no collinearity issues in the formative items. In addition, all the formative items' outer weights were insignificant at $\mathrm{p}<0.005$ nevertheless they were not removed from the analysis because their outer loadings were above 0.50 as suggested by Hair et al. (2017). In other words, formative items formed the second-order 
formative constructs. In a nutshell, second-order formative measurement model was at the acceptable level.

Table 3: The Results of Formative Items' Variance Inflation Factor (VIF), Outer Weights and Outer Loadings

\begin{tabular}{ccccc}
\hline \hline Second-Order Formative Constructs & Items & VIF & $\boldsymbol{t}$ Values & Outer Loadings \\
\hline Organizational ethical climate & Egoism & 1.191 & $0.872^{*}$ & 0.638 \\
& Benevolence & 1.254 & $1.573^{*}$ & 0.866 \\
& Principled & 1.427 & $0.199^{*}$ & 0.734 \\
\hline \hline
\end{tabular}

\subsection{Assessment of Structural Model}

After that, the researcher proceeded to analyze the structural model of this study. The structural model contained hypothesized relationship between exogenous and endogenous variables in the model (Hair et al., 2017). Structural model accessed collinearity, coefficient of determination $\left(\mathrm{R}^{2}\right)$, effect size $\left(f^{2}\right)$, predictive relevance $\left(\mathrm{Q}^{2}\right)$ and hypothesis testing (Hair et al., 2017). Firstly, as stated by Hair et al. (2017) collinearity of the constructs could be detected from the variance inflation factor (VIF). Variance inflation factor (VIF) of ability- (i.e 1.972), motivation- (i.e 1.713) and opportunity- (i.e 1.453) enhancing HRM practices were less than 5. Hence, collinearity was not an issue in this study. Secondly, coefficient of determination $\left(\mathrm{R}^{2}\right)$ determined the percentage of variance in the dependent variable that could be explained by one or more independent variable (Hair et al., 2017). It was found that 0.606 , which was $60.6 \%$ of the variance in organizational ethical climate was explained by ability, motivation and opportunity-enhancing HRM practices. Thirdly, effect size $\left(f^{2}\right)$ examined the effect of independent variables on the dependent variables (Hair et al., 2017). Effect size $\left(f^{2}\right)$ values of $0.02,0.15$ and 0.35 represent small, medium and large (Cohen, 1988). The results showed that ability-enhancing HRM practices had large effect of 0.562 on organizational ethical climate. Conversely, motivation- $\left(f^{2=0.001)}\right.$ and opportunity- $\left(f^{2=0.049)}\right.$ enhancing HRM practices had small effect on organizational ethical climate. Fourthly, predictive relevance $\left(\mathrm{Q}^{2}\right)$ explained how well the dependent variables explained by independent variables in the structural model (Chin, 1988). The result derived from blindfolding procedures showed that the research model had predictive relevance $\left(\mathrm{Q}^{2}\right)$ since the predictive relevance $\left(\mathrm{Q}^{2}\right)$ value greater than 0 , which was 0.123 . Fifthly, hypothesis testing was conducted via bootstrapping procedure to generate $t$ values (Hair et al., 2017). Table 4 summarized the results of hypotheses testing. Ability-enhancing HRM practices $(b=0.661, p<0.05)$ were found to have a significant relationship on organizational ethical climate. Thus, $\mathrm{H}_{1}$ was supported. Meanwhile, the relationships between motivation-enhancing HRM practices $(b=0.0021, \mathrm{p}<0.05)$ and opportunity-enhancing HRM practices $(b=0.167, \mathrm{p}<0.05)$ on organizational ethical climate were not significant. Hence, $\mathrm{H}_{2}$ and $\mathrm{H}_{3}$ were not supported.

Table 4: Hypothesis Testing

\begin{tabular}{ccccc}
\hline \hline Hypothesis & Relationship & Standard Beta & $\boldsymbol{t}$ value & Decision \\
\hline $\mathrm{H}_{1}$ & Ability -> OEC & 0.661 & $3.015^{*}$ & Supported \\
$\mathrm{H}_{2}$ & Motivation -> OEC & 0.021 & 0.138 & Not Supported \\
$\mathrm{H}_{3}$ & Opportunity $>$ OEC & 0.167 & 0.734 & Not Supported \\
\hline \hline
\end{tabular}

Note: $\mathrm{OEC}=$ organizational ethical climate, ${ }^{*} t$ value $>1.96=$ significance $<0.05$ 


\section{DISCUSSION}

First of all, the ability-enhancing HRM practices exerted expected a significant association with organizational ethical climate. The organizations achieved organizational ethical climate when the organizations hired the employees that shared similar ethical values and belief with the organizations. Valentine, Hollingworth and Eidsness (2014) confirmed that organizations developed organizational ethical climate by recruiting and selecting ethical employees because they were less likely to engage in workplace wrongdoings. The organizations also recruited qualified candidates based on competency and education instead of personal background. It stimulated organizational ethical climate when qualified candidates were treated fairly, with dignity and respect. Other than that, the organizations extended organizational ethical climate through ethical training. Bradshaw (2013) reported that failure to train staff about the importance of ethical values and how to implement the code of ethics caused the organizations to face integrity risk and reputation damage.

Conversely, motivation-enhancing HRM practices exhibited insignificant relationship with organizational ethical climate. The reason could be the rewards contributed self-interest among the employees within organization. Based on Guerci et al. (2013), employees within organizations were often treated with rewards as the method to achieve their self-interest goals (e.g promotions and commissions). Hence, such self-interested employees within organizations pursued their own benefits until they completely ignored the organizations' success and other stakeholders' benefits. In the similar vein, Wimbush and Shepard (1994) identified that organizations' incentive pay system fostered selfinterest employees and encouraged the employees to be concerned about their paycheck rather than the customers. Thus, it discouraged organizational ethical climate.

In a similar vein, opportunity-enhancing HRM practices were shown to have an insignificant relationship with organizational ethical climate. The possible explanation was the employees within the organizations lacked guidance on how to involve in ethics program and also unclear with their roles and responsibilities in improving ethical standards. Therefore, the effectiveness of organizational ethical climate was likely reduced. Schwartz (2013) pointed out that the greater the understanding of the employees within organizations on their roles in the code of ethics, the greater they complied to the code of ethics and uphold organizational ethical climate. Another possible explanation might be due to the construction companies that participated in this study that were subjected to the code of ethics imposed by the professional association such as the Construction Industry Development Board (CIDB). Consequently, it reduced their contribution in the organizations' ethical policy and resulted in opportunity-enhancing HRM practices had no connection with organizational ethical climate.

\section{RESEARCH IMPLICATIONS}

This study sought to make several theoretical and practical implications. Generally, this study enlarged the AMO-enhancing HRM practices and organizational ethical climate researches by testing the impact of AMO-enhancing HRM practices on organizational ethical climate. However, the finding particularly showed that ability-enhancing HRM practices related with organizational ethical climate. In doing so, it extended future researchers' understanding on how ability-enhancing HRM practices improve organizational ethical climate. Also, the finding revealed motivation- and opportunity-enhancing HRM practices did not have relationship on organizational ethical climate. Despite that, it could be the base for future researches in adding mediators or moderators between these two relationships. The present study contributes to the RBV theory by explaining the relationship between HRM practices (i.e., AMO- 
enhancing) and organisational ethical climate. Nevertheless, result indicated ability-enhancing HRM practices reinforced organizational ethical climate. The finding was important as it broadens the RBV theory by showing that ability-enhancing HRM practices have the potential to promote organisational ethical climate.

From the practical implications, the findings were useful for the managers to establish organizational ethical climate. In this situation, the managers could prioritize the investment of ability-enhancing HRM practices to enhance organizational ethical climate. Recruitment and selection must be designed to hire and select the candidates based on ethical values and principles. Ethical values and principles could be accessed through face to face interviews whereby the candidates asked to describe previous organization's ethics. Hence, the recruitment and selection based on the tendency to comply ethical values and principles increase the probability of new staff to exhibit ethical behaviors. This enabled to achieve organizational ethical climate. Besides that, training and development confirmed to the code of ethics provide the chances for the organizational members to gain more understanding about how code of ethics influenced their job tasks. Thus, it leads to organizational ethical climate. On the other hand, organizations could utilize long term rewards (e.g flexible hours, a thank you note) to motivate organizational members to display ethical behaviors because it did not diminished ethical behaviors (Guerci et al., 2015).

\section{LIMITATIONS AND DIRECTIONS FOR FUTURE RESEARCH}

There were a few limitations in this study. Firstly, the data were solely collected from construction companies in Malaysia. Therefore, the findings were prone to a single sourced bias and not suitable to generalize to other countries and other business industries. As a result, the researcher advised future studies to examine this study in different countries and business industries. Secondly, the sample size of this study was relatively small. It influenced the generalizations and interpretations of the findings. Thus, future research should be based on large sample sizes to confirm the findings. Thirdly, this study primarily relied on the perceptions of the representative (i.e executive director or managing director or human resource manager) of each participated construction companies in Malaysia and generated a cognitive bias problem. There was a potential that the representative preferred to choose the socially desirable answers rather than expressing their opinions honestly. As such, future studies might reduce this possibility by assuring the respondents about confidentiality. Fourthly, this study had a crosssectional design. It provided static relationships between organizational ethical climate and AMOenhancing HRM practices. Thus, future researches should consider about longitudinal studies because it can explain how the interventions of ability-enhancing HRM practices could gradually improve the organizational ethical climate.

\section{CONCLUSION}

Overall, this study revealed that there was a strong relationship between ability-enhancing HRM practices and organizational ethical climate. It implied the significant role of ability-enhancing HRM practices on organizational ethical climate. This meant that the greater the ability-enhancing HRM practices, the greater the development of organizational ethical climate. Hence, it was important for construction companies in Malaysia to utilize on the ability-enhancing HRM practices (e.g ethical hiring, selection and training) in order to increase organizational ethical climate. 


\section{REFERENCES}

Abu Bakar, L. J., \& Ahmad, H. (2010). Assessing the relationship between firm resources and product innovation performance: A resource-based view. Business Process Management Journal, 16(3), 420-435.

Arulrajah, A. A. (2015). Contribution of human resource management in creating and sustaining ethical climate in organizations. Sri Lankan Journal of Human Resource Management, 5(1), 31-44.

Bagozzi, R. P., \& Yi, Y. (1988). On the evaluation of structural equation models. Journal of the Academy of Marketing Science, 16(1), 74-94.

Barnett, T., \& Vaiceys, C. (2002). The moderating effect of individual's perceptions of ethical work climate on ethical judgments and behavioral intentions. Journal of Business Ethics, 27(4), 351-362.

Barney, J. B. (1986). Organizational culture: can it be a source of sustained competitive advantage? Academy of Management Review, 11(3), 656-665.

Barney, J. B. (1992). Integrating organizational behavior and strategy formulation research: A resourcebased analysis. In P. Shrivastava, A. Huff \& J. Dutton (Eds.), Advances in strategic management (39-61). Greenwich, CT: JAI Press.

Barney, P. (1991). Firms resources and sustained competitive advantage. Journal of Management, 17(1), 99-120.

Becker, J. M., Klein, K., \& Wetzels, M. (2012). Models in PLS-SEM: Guidelines for using reflectiveformative type models. Long Range Planning, 45(5-6), 359-394.

Bello-Pintado, A. (2015). Bundles of HRM practices and performance: empirical evidence from a Latin American context. Human Resource Management Journal, 25(3), 311-330.

Bhardwaj, B. R. (2016). Role of green policy on sustainable supply chain management: A model for implementing corporate social responsibility (CSR). Benchmarking: An International Journal, 23(2), 456-468.

Bonini, S. (2017). The business of sustainability: McKinsey global survey results. Retrieved from http://www.mckinsey.com/business-functions/sustainability-and-resource-productivity/ourinsights/the-business-of-sustainability-mckinsey-global-survey-results at 12 July 2017

Bradshow, K. (2013). Sourcing effective scenarios for use in business ethics training. Industrial and Commercial Training, 45(5), $264-268$.

Branco, M. C., \& Rodrigues, L. L. (2006). Corporate social responsibility and resource-based perspectives. Journal of Business Ethics, 69(2), 111-132.

Bruns, D. E., Burtis, C. A., Gronowski, A. M., McQueen, M. J., Newman, A., \& Jonsson, J. (2015). Variability of ethics education in laboratory medicine training programs: Results of an international survey. Clinica Chimica Acta, 442, 115-118.

Chan, E. S. W., Hon, A. H. Y., Chan, W., \& Okumus, F. (2014). What drives employees' intentions to implement green practices in hotels? The role of knowledge, awareness, concern and ecological behaviour. International Journal of Hospitality Management, 40, 20-28.

Chin, W. W. (1998). The partial least squares approach to structural equation modeling. Marcoulides, G. A. (Eds.), Modern Business Research Methods (pp. 295-336). Mahwah: New Jersey.

Cohen, J. (1988), Statistical power analysis for the behavioral sciences. Hillsdale, USA: Erlbaum.

Cullen, J. B., Victor. B., \& Bronson, J. W. (1993). The ethical climate questionnaire: an assessment of its development and validity. Psychological Reports, 73(2), 667-674.

Dubey, R., Gunasekaran, A., Childe, S. J., Papadopoulos, T., Hazen, B., \& Giannakis, M. (2017). Examining the effect of external pressures and organizational culture on shaping performance measurement systems (pms) for sustainability benchmarking: some empirical findings. International Journal of Production Economics, 193, 63-76. 
Durrani, A. S., \& Rajagopal, L. (2016). Restaurant human resource managers' attitudes towards workplace diversity, perceptions and definition of ethical hiring. International Journal of Hospitality Management, 53, 145-151.

Eccles, R. G., Ioannou, I., \& Serafeim, G. (2014). The impact of corporate sustainability on organizational processes and performance. Management Science, 60(11), 2835-2857.

Faul, F., Erdfelder, E., Lang, A. G., \& Buchner, A. (2007). G*Power 3: A flexible statistical power analysis program for the social, behavioral, and biomedical sciences. Behavior Research Methods, 39(2), 175-191.

Foote, M. F., \& Ruona, W. E. A. (2008). Institutionalizing ethics: A synthesis of frameworks and the implications for HRD. Human Resource Development Review, 7(3), 292-308.

Galpin, T., Whitttington, J. L., \& Bell, G. (2015). Is your sustainability strategy sustainable? Creating a culture of sustainability. Corporate Governance, 15(1), 1-17.

Garavan, T. N., \& McGuire, D. (2010). Society: human resource development's role in embedding corporate social responsibility, sustainability and ethics in organizations. Advances in Developing Human Resource, 12(5), 487-507.

Gardner, T. M., Wright, P. M., \& Moynihan, L. M. (2011). The impact of motivation, empowerment, and skill-enhancing practices on aggregate voluntary turnover: the mediating effect of collective affective commitment. Personnel Psychology, 64(2), 315-350.

Geng, R., Mansouri, S. A., \& Aktas, E. (2017). The relationship between green supply chain management and performance: A meta-analysis of empirical evidences in Asian emerging economies. International Journal of Production Economics, 183(Part A), 245-258.

Ghosh, K. (2015). Benevolent leadership in not-for-profit organizations. Leadership \& Organization Development Journal, 36(5), $592-611$

Guerci, M., Radaelli, G., Battisi, F. D., \& Siletti, E. (2017). Empirical insights on the nature of synergies among HRM policies - An analysis of an ethics-oriented HRM system. Journal of Business Research, 71, 66-73.

Guerci, M., Radaelli, G., Siletti, E., Cirella, S., \& Rami Shani, A. B. (2013). The impact of human resource practices and corporate sustainability on organizational ethical climates: an employee perspectives. Journal Business Ethics, 126(2), 325-342.

Hair, J. F., Hult, G. T. M., Ringle, C. M., \& Sarstedt, M. (2017). A Primer on Partial Least Squares Structural Equation Modeling. Thousand Oaks: Sage.

Hamimah, A., Norfashiha, H., Norazian, M. Y., \& Norizan, A. (2012). Ethical issues in the construction industry: Contractor's perspective. Procedia - Social and Behavioral Sciences, 35, 719 - 727.

Hamzah, A. R., Wang, C., \& Yap, X. W. (2010). How professional ethics impact construction quality: perception and evidence in a fast developing economy. Scientific Research and Essay, 5(23), 3742-3749.

Henseler, J., Ringle, C. M., \& Sarstedt, M. (2015). A new criterion for assessing discriminant validity in variance-based structural equation modeling. Journal of the Academy of Marketing Science, 43(1), 115-135.

Hulland, J. (1999). Use of partial least squares (PLS) in strategic management research: a review of four recent studies. Strategic Management Journal, 20(2), 195-204.

Jabbour, C. J. C., Mauricio, A. L., \& Jabbour, A. B. L. D. S. (2017). Critical success factors and green supply chain management proactivity: shedding light on the human aspects of this relationship based on cases from the Brazilian industry. Production Planning \& Control, 28(6-8), 671-683.

Jang. Y. J., Zheng, T., \& Bosselman, R. (2017). Top managers' environmental values, leadership, and stakeholder engagement in promoting environmental sustainability in the restaurant industry. International Journal of Hospitality Management, 63, 101-111. 
Jiang, K., Lepak, D. P., Han, K., Hong, Y., Kim, A., \& Winkler, A. L. (2012). Clarifying the construct of human resource systems: Relating human resource management to employee performance. Human Resource Management Review, 22(2), 73-85.

Kiron, D., Unruh, G., Kruschwitz, N., Reeves, M., Rubel, H., \& Zum Felde, A. M. (2017). Corporate sustainability at a crossroads. Retrieved from http://sloanreview.mit.edu/projects/corporatesustainability-at-a-crossroads/ at 12 July 2017

Lado, A. A., \& Wilson, M, C. (1994). Human resource systems and sustained competitive advantage: a competency based perspective. Academy of Management Review, 19(4), 699-727.

Lau, P. Y. Y., Tong, J. L. Y. T., Lien, B. Y. H., \& Hsu, Y. C. (2017). Ethical work climate, employee commitment and proactive customer service performance: Test of the mediating effects of organizational politics. Journal of Retailing and Consumer Services, 35, 20-26.

Luria, G., \& Yagil, D. (2008). Procedural justice, ethical climate and service outcomes in restaurants. International Journal of Hospitality Management, 27(2), 276-283.

Mackenzie, S. B., Podakoff, P. M. \& Jarvis, C. B. (2005). The Problem of Measurement Model Misspecification in Behavioral and Organizational Research and Some Recommended Solutions. Journal of Applied Psychology, 90(4), 710 -730.

Manroop, L. (2015). Human resource systems and competitive advantage: an ethical climate perspective. Business Ethics: A European Review, 24(2), 186-204.

Manroop, L., Singh, P., \& Ezzedeen, S. (2014). Human resource systems and ethical climates: a resource based perspective. Human Resource Management, 53(5), 795-816.

Marshall, D., McCarthy, L., McGGrath, P., \& Claudy, M. (2015). Going above and beyond: how sustainability culture and entrepreneurial orientation drive social sustainability supply chain practice adoption. Supply Chain Management: An International Journal, 20(4), 434-454.

Martin, K. D., \& Cullen, J. B. (2006). Continuities and extensions of ethical climate theory: a metaanalytic review. Journal of Business Ethics, 69(2), 175-194.

Martin-de Castro, G., Amores-Salvado, J., Navas-Lopez, J. E., Balarezo-Nunez, R. M. (2017). Exploring the nature, antecedents and consequences of symbolic corporate environmental certification. Journal of Cleaner Production, 164, 664-675.

Mossholder, K. W., Richardson, H. A., \& Settoon, R. P. (2011). Human resource systems and helping in organizations: A relational perspective Academy of Management Review, 36(1), 33-52.

Nasibulina, A. (2015). Education for Sustainable Development and Environmental Ethics. ProcediaSocial and Behavioral Sciences, 214, 1077-1082.

Nulty. D.D. (2008). The adequacy of responses rate to online and paper surveys: What can be done. Assessment and Evaluation in Higher Education, 33(3), 301-304.

Ogunfowara, B. (2014). The impact of ethical leadership within the recruitment context: The roles of organizational reputation, applicant personality and value congruence. The Leadership Quarterly 25(3), 528-543.

Özçelik, G., Aybas, M., \& Uyargil, C. (2016). High performance work systems and organizational values: Resource-based view considerations. Procedia-Social and Behavioral Sciences, 235, 332-341.

Parboteeah, K. P., \& Kapp, E. (2008). Ethical climates and workplace safety behaviors: an empirical investigation. Journal of Business Ethics, 80(3), 515-529.

Parboteeah, K. P., Chen, H. C., Lin, Y. T., Chen, I. H., Lee, A. Y. P., \& Chung, A. (2010). Establishing organizational ethical climates: how do managerial practices work? Journal of Business Ethics, 97(4), 599-611.

Parboteeah, K. P., Seriki, H. T., \& Hoegl, M. (2014). Ethnic diversity, corruption and ethical climates in sub-Saharan Africa: recognizing the significance of human resource management. The International Journal of Human Resource Management, 25(7), 979-1001. 
Porter, T. H., Gallagher, C. V., Lawong, D. (2016). The greening of organizational culture: revisited fifteen years later. American Journal of Business, 31(4), 206-226.

Raile, E. D. (2012). Building ethical capital: perceptions of ethical climate in the public sector. Public Administration Review, 73(2), 253-262.

Reed, R., \& DeFillippi, R. (1990). Casual ambiguity, barriers to imitation and sustainable competitive advantage. Academy of Management Review, 15(1), 88-102.

Roscoe, J. T. (1975). Fundamental research statistics for the behavioral science. New York: Holt, Rinehart and Winston.

Schneider, B. (1983). Work Climates: an interactionism perspective. In N. W. Feimer, \& E. S. Geller (Eds.), Environmental Psychology: Directions and Perspectives. New York: Praeger.

Schwartz, M. S. (2013). Developing and sustaining an corporate ethical culture. Business Horizons, 56(1), 39-50.

Sekaran, U. \& Bougie, R. (2013). Research Methods for Business: A Skill Building Approach. New Delhi: Wiley India.

Shaffer, F. A., Mukhshi, B., \& Kim, E. M. (2015). Business case for ethical recruitment. Nurse Leader, $13(5), 40-48$.

Sroufe, R. (2017). Integration and organizational change towards sustainability. Journal of Cleaner Production, 162, 315-329.

Subramony, M. (2009). A meta-analytic investigation of the relationship between HRM bundles and firm performance. Human Resource Management, 48(5), 745-768.

Theodoulidis, B., Diaz, D., Crotto, F., \& Rancati, E. (2017). Exploring corporate social responsibility and financial performance through stakeholder theory in the tourism industries. Tourism Management, 62, 173-188.

Thite, M. (2013). Ethics and human resource management and development in a global context: case study of an Indian multinational. Human Resource Development International, 16(1), 106-115.

Ulrich, D. \& Lake, D. (1990). Organizational capability. New York: Wiley.

Valentine, S., Hollingworth, D., \& Eidsness, B. (2014). Ethics-related selection and reduced ethical conflict as drivers of positive work attitudes. Personnel Review, 43(5), 692-716.

Victor, B., \& Cullen, J. B. (1988). The organizational bases of ethical work climates. Administrative Science Quarterly, 33(1), 101-125.

Vilchez, V. F., Darnall, N., \& Aragon-Correa, J. A. (2017). Stakeholder influences on the design of firms' environmental practices. Journal of Cleaner Production, 142(20), 3370-3381.

Weber, J. \& Geder, V. W. (2011). Organizational role and environmental uncertainty as influences on ethical work climate in military units. Journal of Business Ethics, 100(4), 595-612.

Weinstein, D. (2012). The psychology of behaviorally-focused resume's on applicant selection: Are your hiring managers really hiring the 'right' people for the 'right' jobs? Business Horizons, 55(1), 53-63.

Wimbush, J. C., \& Shepard, J. M. (1994). Toward an understanding of ethical climate: its relationship to ethical behavior and supervisory influence. Journal of Business Ethics, 13(8), 637-647.

Wright, P. M., \& McMahan, G. C. (1992). Theoretical perspective for strategic human resource management. Journal of Management, 18(2), 295-320.

Wright, P. M., Dunford, B. B. \& Snell, S. A. (2001). Human resources and the resource-based view of the firm. Journal of Management, 27(6), 701-721.

Zientara, P \& Zamojska, A. (2016). Green organizational climates and employee pro-environmental behaviour in the hotel industry. Journal of Sustainable Tourism, 24(6), 1-18. 